\title{
SELECTED DOCUMENTS
}


B.S. Chimni, Miyoshi Masahiro, and Surya P. Subedi - 9789047418306 Downloaded from Brill.com04/26/2023 01:20: ๑९PM via free access 


\title{
THE SECOND BANDUNG DECLARATION ON THE NEW ASIAN-AFRICAN STRATEGIC PARTNERSHIP
}

\author{
Declaration on the New Asian-African Strategic Partnership
}

\section{April 2005}

We, the Leaders of Asian and African countries, have gathered in Jakarta, Indonesia, on 22-23 April 2005 for the Asian-African Summit to reinvigorate the Spirit of Bandung as enshrined in the Final Communiqué of the 1955 Asian-African Conference and to chart the future cooperation between our two continents towards a New Asian-African Strategic Partnership (NAASP).

We reiterate our conviction that the Spirit of Bandung, the core principles of which are solidarity, friendship and cooperation, continues to be a solid, relevant and effective foundation for fostering better relations among Asian and African countries and for resolving global issues of common concern. The 1955 Bandung Conference remains as a beacon in guiding the future progress of Asia and Africa.

We note with satisfaction that since the 1955 Conference, Asian and African countries have attained significant political advances. We have successfully combated the scourge of colonialism and consistently fought racism. In particular, the abolishment of apartheid represents a milestone in Asian-African cooperation, and we reaffirm our continued determination to eradicate racism and all forms of discrimination. As a result of our efforts over the last fifty years, we are all independent, sovereign and equal nations striving for the promotion of human rights, democracy, and the rule of law. However, having made these political gains, we are concerned that we have not yet attained commensurate progress in the social and economic spheres. We recognize the need continuously to strengthen the process of nation and state-building, as well as social integration.

We remain committed to the principle of self-determination as set forth in the Final Communiqué of the 1955 Bandung Conference and in accordance with the Charter of the United Nations. In particular, we express our abhorrence that, fifty years after the 1955 Bandung Conference, the Palestinian people remain deprived of their right to independence. We remain steadfast in our support for the Palestinian people and the creation of a viable and sovereign Palestinian state, in accordance with relevant United Nations resolutions.

Asian Yearbook of International Law, Volume 11 (B.S. Chimni et al., eds.)

(C) 2006 Koninklijke Brill NV. Printed in The Netherlands, pp. 343-346. 
We emphasize the importance of multilateral approaches to international relations and the need for countries strictly to abide by the principles of international law, in particular the Charter of the United Nations. As Asia and Africa represent the majority in the community of nations, we reaffirm the need to support and strengthen multilateralism in order to address global issues, including reforming multilateral institutions.

We recognize that the current global situation and the prevailing conditions in Asia and Africa necessitate the need actively to pursue a common view and collective action to ensure the equitable sharing of the benefits of globalization. We are determined to meet the internationally agreed targets and goals aimed at poverty eradication, development and growth, and underline the necessity for all parties to honour their commitments in this regard. We emphasize the importance of enhancing cooperation with all regions.

We underline the importance of dialogue among civilizations to promote a culture of peace, tolerance, and respect for religious, cultural, language, and racial diversities as well as gender equality.

We acknowledge the positive development of intra-regional/sub-regional integration in both continents. Nevertheless, continent-wide inter-regional cooperation among the two continents needs to be developed. We are convinced that cooperation between sub-regional organizations, through sharing experiences and best practices, can propel growth and sustainable development.

We underline the importance of bringing the regions closer together by utilizing the advantages derived from the commonalities and diversity of, as well as the new and encouraging developments in, both regions. We emphasize both the collective responsibilities and the important role of all stakeholders in exploring innovative and concrete ways and means to strengthen cooperation between Asia and Africa.

In this regard, we acknowledge the importance of complementing and building upon existing initiatives that link the two continents, inter alia, Tokyo International Conference on African Development (TICAD), China-Africa Cooperation Forum (CACF), India-Africa Cooperation, Indonesia-Brunei Darussalam sponsored Non-Aligned Movement Centre for South-South Technical Cooperation, Vietnam-Africa Business Forum, the Smart Partnership Initiative, and the Langkawi International Dialogue. We stress the importance of streamlining and aligning existing initiatives for coherence and maximum benefit and to avoid duplication.

We acknowledge the New Partnership for Africa's Development (NEPAD) as the African Union's programme for poverty eradication, socio-economic development and growth and accept it as the framework for engagement with Africa. We express our support for the implementation of NEPAD. 
We underscore the urgency of promoting economic development in the Asian and African regions, as stipulated in the 1955 Bandung Conference. We stress that poverty and under-development, gender mainstreaming, communicable diseases, environmental degradation, natural disasters, drought and desertification, digital divide, inequitable market access, and foreign debt remain as issues of common concern which call for our closer cooperation and collective action.

We envision an Asian-African region at peace with itself and with the world at large working together as a concert of nations in harmony, non-exclusive, bonded in dynamic partnership and conscious of our historical ties and cultural heritage. We visualize an affluent Asian-African region characterized by equitable growth and sustainable development as well as a common determination to enhance the quality of life and well-being of our people. We further envisage a caring Asian-African society where the people live in stability, prosperity and dignity, free from the fear of violence, oppression and injustice.

To this end, we hereby declare, as an expression of our new political will, the establishment of a New Asian-African Strategic Partnership (NAASP) as a framework to build a bridge between Asia and Africa covering three broad areas of partnership, namely political solidarity, economic cooperation, and socio-cultural relations. The strategic partnership provides a momentum in achieving peace, prosperity and progress, and will be based on the following principles and ideals:

1. The Ten Principles of Bandung of the 1955 Asian - African Conference;

2. Recognition of diversity between and within the regions, including different social and economic systems and levels of development;

3. Commitment to open dialogue, based on mutual respect and benefit;

4. Promotion of non-exclusive cooperation by involving all stakeholders;

5. Attainment of practical and sustainable cooperation based on comparative advantage, equal partnership, common ownership and vision, as well as a firm and shared conviction to address common challenges;

6. Promotion of sustainable partnership by complementing and building upon existing regional/sub-regional initiatives in Asia and Africa;

7. Promotion of a just, democratic, transparent, accountable and harmonious society;

8. Promotion and protection of human rights and fundamental freedoms, including the right to development;

9. Promotion of collective and unified efforts in multilateral fora.

The NAASP shall emphasize the need to promote practical cooperation between the two continents in areas such as trade, industry, investment, finance, tourism, information and communication technology, energy, health, transportation, agriculture, water resources, and fisheries. 
The NAASP shall also address issues of common concern, such as armed conflict, weapons of mass destruction, transnational organized crimes, and terrorism, which are fundamental to ensuring peace, stability, and security.

We are determined to prevent conflict and resolve disputes by peaceful means and endeavour to explore innovative mechanisms for confidence building and dispute resolution as well as for post- conflict peace-building.

The NAASP shall promote human resource development, enhanced capacity building and technical cooperation in order to create an enabling environment for the betterment of the regions.

We resolve that the sustainability of the NAASP shall be conducted through three tiers of interaction: an intergovernmental forum; sub-regional organizations, and people-to-people interaction, particularly business, academia, and civil society.

We are determined to develop an institutionalized process of the NAASP through convening: a Summit of Heads of State/Government every four years; a Ministerial Meeting of Foreign Ministers every two years; and Sectoral Ministerial and other Technical Meetings when deemed necessary. A Business Summit in conjunction with the Summit of Heads of State/Government will be held every four years.

We pledge to our peoples our joint determination and commitment to bringing the NAASP into reality by implementing concrete actions for the benefit and prosperity of our peoples.

Done in Bandung, Indonesia, on the Twenty-fourth of April in the year Two Thousand and Five, in conjunction with the Commemoration of the Golden Jubilee of the AsianAfrican Conference of 1955. 